\title{
Moon light and the activity patterns of Baird's tapir in the Calakmul region, Southern México
}

\author{
Khiavett Sánchez-Pinzón ${ }^{1 *}$, Rafael Reyna-Hurtado ${ }^{1}$ and Ninon F. V. Meyer ${ }^{1}$ \\ ${ }^{1}$ El Colegio de la Frontera Sur Unidad Campeche. Av. Rancho Polígono 2a, CP. 24500, Lerma. Campeche, México. Email: \\ kgsanchez@ecosur.edu.mx (KS-P), rreyna@ecosur.edu.mx (RR-H), nfmeyer@ecosur.edu.mx (NFVM). \\ ${ }^{*}$ Corresponding author
}

\begin{abstract}
The Baird's tapir (Tapirella bairdii) is an endangered species throughout its distribution area, however many aspects of its biology and ecology have been poorly studied, due to its evasive behavior and low densities. The goal of this study was to evaluate the activity patterns of $T$. bairdii, a large ungulate species from the Neotropics, in relation to moon phases in two sites with different degree of human perturbation: the Calakmul Biosphere Reserve (CBR) and the Nuevo Becal (NB) community. We monitored twenty waterbodies in each site for 18 months using camera traps. The photographic capture rate (CR) and the corresponding moon phases for both sites were recorded. The CR of $T$. bairdii was 0.054 in NB and 0.029 in CBR. T. bairdii was more active at night and dawn-twilight periods. In general, T. bairdii showed major activity during the dark moon phases but the differences with the light phases were not statistically significant. However, we found a trend of tapirs to be more active in dark nights and in the darkest hours in NB than CBR. The apparent preferences for dark nights in NB could be caused by the perturbation caused by human activities at site, which may have influenced the behavior of the tapir that avoid moving out in periods of abundant light in disturbed sites. More research is needed to confirm this finding.
\end{abstract}

El tapir de Baird (Tapirella bairdii) es una especie amenazada en toda su área de distribución, sin embargo, muchos aspectos de su biología y ecología han sido poco estudiados, debido a su comportamiento evasivo y a sus bajas densidades poblacionales. El objetivo de este estudio fue evaluar los patrones de actividad de T. bairdii en relación con las fases lunares en dos sitios con diferente grado de perturbación humana: la Reserva de la Biosfera de Calakmul (RBC) y el Ejido Nuevo Becal (NB). Se monitorearon 20 cuerpos de agua durante18 meses mediante el método de foto-trampeo. Se determinó la tasa de captura (TC) y se registraron las fases lunares correspondientes para ambos sitios. La TC de T. bairdii tapir fue de 0.054 en NB y de 0.029 en la RBC. T. bairdii fue más activo en el periodo nocturno-crepuscular. En general, T.bairdii. mostro una actividad importante durante las fases de oscuridad, pero estas diferencias no fueron significativas estadísticamente. Sin embargo, se encontró una tendencia de los tapires a moverse activamente en las noches y en las horas más obscuras en NB que en RBC. La preferencia aparente por las noches más obscuras en NB podría ser evidencia de la respuesta por parte de los tapires a la perturbación causada por actividades humanas en ese sitio, mostrando un cambio en su comportamiento evitando salir en periodos de abundante luz en sitios perturbados. Sin embargo, se requiere de mayor investigación para corroborar esta posibilidad.

Keys words: behavior; camera trap; human perturbation; luminosity; moon phases.

(c) 2020 Asociación Mexicana de Mastozoología, www.mastozoologiamexicana.org

\section{Introduction}

The Baird's tapir (Tapirella bairdii, or usually known as Tapirus bairdii, see: Ruiz-Garcia et al. 2012, we use Tapirella in this study) is the largest terrestrial mammal of the Neotropics (Emmons and Feer 1997) and plays an important role in the forest dynamics through seed dispersal and predation (O'Farrill et al. 2013; Camargo-Sanabria and Mendoza 2016). Currently, the tapir is listed as endangered both globally (International Union for the Conservation of Nature) and in México (NOM-059-ECOL- 2010; SEMARNAT 2010) mainly due to uncontrolled hunting and habitat loss and fragmentation.

Tapirella bairdii is a solitary animal that can exhibit both diurnal and nocturnal behavior, even though several studies showed that they tend to be more active at night and crepuscular periods (Carbajal-Borges et al. 2014), probably because of the difficulty to dissipate the body heat, a situation that is common to all large animals (Randall et al. 1998; Foerster and Vaughan 2002). According to this, Tapirella bairdii would avoid the hottest hours of the day and restrict their movements to the cool hours of the day (Padilla and Dowler 1994; Foerster and Vaughan 2002). Moreover, sev- eral authors have observed differences in the activity patterns of this specie when other factors such as seasonality, sex, age of the individuals and moon light intensity were taken into account (Lizcano and Cavalier 2000, 2004; Foerster and Vaughan 2002; Tobler 2002; Holden et al. 2003; Noss et al. 2003; Norvarino et al. 2005; Medici 2010).

Although there is evidence showing that, some species with night habits reduce the intensity of their activity during nights with full moon in an effort to reduce the risk of predation by natural predators and/or humans (Prugh and Golden 2014); studies on the variation of activity patterns respect to moon light of tapir species have not lead to conclusive results yet. While Lizcano and Cavallier (2000) recorded a major nocturnal activity of the Mountain tapir (Tapirus pinchaque) during full moon phase, Medici (2010) found an opposite behavior pattern for the Lowland tapir (Tapirus terrestris) that tended to reduce its movements in full moon nights in the Brazilian Atlantic Forest. Besides, Tapirus terrestris did not seem to respond to the moon phases in the Brazilian Pantanal (Coelho et al. 2008).

In addition to the moon phase, tapirs activity can also be influenced by human activities; in areas where hunting, 
habitat encroachment and other non-timber extractive activities, and even ecotourism occur, tapirs can become completely nocturnal (Naranjo and Cruz 1998; Foerster and Vaughan 2002; Wallace et al. 2002). In this sense it has been confirmed that some species become nocturnal in areas where predators are abundant or where there is high hunting pressure (Griffiths and van Schaik, 1993, Ripple et al. 2001, Gaynor et al. 2018).

Despite several studies have investigated the effect of predation and hunting pressure independently, the relationship that may exist among daily activity patterns, moon phases and human perturbation is still unknown for most of the sites where tapir species inhabit. Therefore, the goal of this study was to evaluate the activity patters of Tapirella bairdii in relation to moon phases in two sites with contrasting degree of human perturbation: the Calakmul Biosphere Reserve (CB) and the Nuevo Becal community (NB). Our aim is to contribute to understand the species behavior under changes in luminosity due to different moon phases and if this interacts with different degrees of human perturbation in the forest. This information is relevant to advance in the knowledge of the behavior of wild Tapirella bairdii.

\section{Material and Methods}

Study site. This study took place in the Calakmul Biosphere Reserve (CBR) and the nearby forested community of Nuevo Becal (NB). Both sites are located in the Yucatán Peninsula in Southern México (Figure 1), that is principally covered by subhumid tropical forest that is marked by a dry season from January to May. During the wet season that usually occurs from June through December, precipitation ranges from 700 to $2,000 \mathrm{~mm}$. The temperature average $25^{\circ} \mathrm{C}$ all year long (García-Gil 2003). The vegetation types in the area are mainly humid tropical forest classified as 1) medium, semi-perennial forest; 2) low-flooded forest; 3 ) low-dry forest, and 4) secondary vegetation (Pennington and Sarukhán 1998). In the NB community there is a major coverage of medium, semi-perennial forest and larger ponds than in the CBR (Reyna-Hurtado and Tanner 2007).

Because of the geological structure of the Calakmul region of carbonate origin, there are not permanent water sources and most of the rainfall percolate to the underground, only in few specific places the water accumulated in the surface. These ponds, locally known as "aguadas" are source of water for wildlife and for many human communities of the region during the dry season (Reyna-Hurtado et al. 2010).

The CBR has an extent of $7,231 \mathrm{~km}^{2}$ and was created in 1989. The area is protected by guards posted in two checkpoints at the entrance of the only road that leads toward the area and the only activities allowed inside are research and low-impact tourism, which are concentrated mostly around the Calakmul archeological city. The NB community is located at the eastern side of the CBR and comprises $520 \mathrm{~km}^{2}$, was created in 1970 . In this community, the most important activities are seasonal crops such as corn and beans, non-timber products extraction especially honey, charcoal and seeds, and subsistence hunting. This community still maintains forest in well stage of conservation in an approximately $80 \%$ of its area (Reyna-Hurtado 2009). Also, there are two wildlife management and conservation units locally known as UMAS (Unidad de Manejo y Aprovechamiento de Fauna, in Spanish) where sport hunting take place usually once per year. These units aim to harvest mainly tropical deer (Mazama sp.) and wild turkey (Agriocharis ocellata).

Camera trapping. Twenty ponds (10 in each site) were monitored by setting up a single camera trap (Reconyx PC800 Hyperfire professional Reconyx, Inc) at $50 \mathrm{~cm}$ high in each pond from January 2014 to June 2015. The ponds were selected in a way that they would be at least $1.5 \mathrm{~km}$ away from each other. The cameras were programmed to take five consecutive photos (1 photo per second) each time the sensor detected movement and were checked every two months to change batteries and memory cards.

We used a 2-hour filter between tapir sequences to avoid having repetitive sequences of the same individual, unless individuals could clearly be distinguished, e. $g$. female vs male; adult vs juveniles, or individual with unique marks or scars. We determined the capture rate (CR) using classical method for each site (RBC and NB) with the following equation: $C R=N / S E^{*} 1000$ camera-trap days. With $N=$ number of records and $\mathrm{SE}=$ sampling effort measured as the number of days multiplied by the number of cameras.

We examined tapir daily activity patterns in NB and RBC by using the capture events in each site. We represented the corresponding activity patterns in a graph that was generated with the software 'Overlap' (Meredith and Ridout 2014) using software $\mathrm{R}$ ( $\underline{\mathrm{R} \text { Core Team, 2018, }} \mathrm{R}$ Studio ver. 1.1.463). After conversion of time to radians, the activity data from

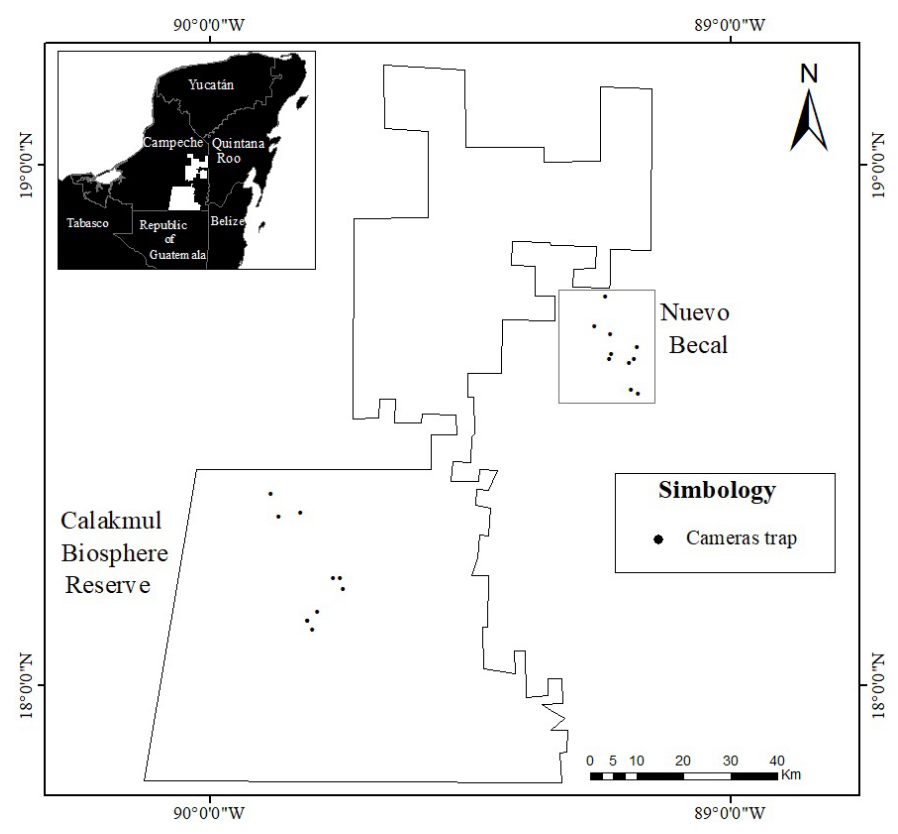

Figure 1. Study area with boundaries of the Calakmul Biosphere Reserve (CBR) and the community of Nuevo Becal (NB), with the location of the "aguadas" that were surveyed. 
each site were subjected to a Rayleigh Test of Uniformity $(Z)$, this analyses test if the data distribution differs from a uniform distribution (Zar 2010). Patterns of activity were described using non-parametric kernel density estimations. The proportion of overlap in activity (the coefficient of overlap, $\Delta$ ), was estimated between sites. Because samples were greater of 75 records, the coefficient of overlap $\Delta 4$, was used to estimate activity overlap, as suggested by Meredith and Rideout (2014). The confidence interval (Cl) between lower and upper $95 \%$ limits in estimates of species activity overlap calculated as percentile intervals from 1000 bootstrap samples (Ridout and Linkie 2009).

Variations in the activity pattern in relation with the different moon phases were analyzed based on a moon calendar specific for the study area and the sampled period (obtained from the website www.tutiempo.net). Only the records between 18:30 and 6:00 hr were analyzed and classified according to the corresponding lunar phase. The moon phases were: dark phases, moon presents less than $50 \%$ luminosity (new moon; waxing crescent; waning crescent), and light phases, moon presents more than 50 \% luminosity (full moon; waxing gibbous; waning gibbous). To test for differences in the activity of Tapirella bairdii according to the different moon phases (dark phase vs. light phase) in all sampled ponds and in the different sites, we first tested for normality of the data with a Kolmogorov-Smirnov test, and then we conducted a paired t-test for each site to compare the frequency of records obtained in each phase. Finally, an ANOVA test was used to examine the differences between the frequencies of the records (number of photos obtained in one of the two moon phases) obtained in each phase between seasons for each site. The analyzes were conducted in SPSS Inc. (Statistical Package for Social Sciences), version 16.0. Chicago.

\section{Results}

Capture rate. The sampling effort was similar in both sites, with a total of 3,244 trapping nights in NB and 3,384 trapping nights in $C B R$, but the $C R$ was almost twice higher in NB ( $C R=54$ records for 1,000 days/tramp) than in CBR ( $C R=29$ records for 1,000 days/tramp).

Activity patterns. Tapirs presented an unimodal activity patterns in both sites (CBR: $Z=33.03, P=0.001$ and NB: $Z=23.20, P=0.001$ ), with a large activity peak between 19:00 to 5:00 hr (Figure 2). The level of tapir's activity overlap was high: $\Delta=0.86$ (95\% confidence interval: 0.77 to 0.93 ) between sites (Figure 3a); $\Delta=0.86$ (95\% confidence interval: 0.78 to 0.93 ) in the dry season and $\Delta=0.71$ (95\% confidence interval: 0.55 to 0.85 ) in rainy season (Figure $3 b$ ). The overlap in the activity patterns in the different phases was: RBC $\Delta=0.67$ (95\% confidence interval: 0.46 to 0.73 ); with the large activity peak between 20:00 to $22: 00 \mathrm{hr}$ in the dark phases and between 0:00 to 1:00 hr in the light phases (Figure 3c); NB $\Delta=0.77$ (95\% confidence interval: 0.60 to 0.95); with the large activity peak between $20: 00$ to $0: 00 \mathrm{hr}$

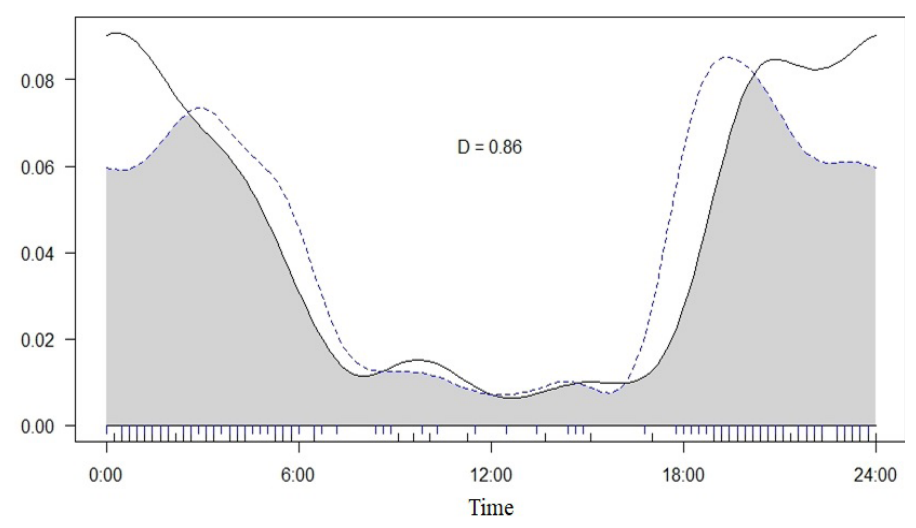

Figure 2. Proportion of overlap ( $D=$ level of overlap) in activity patterns of Tapirella bairdii in the Calakmul Biosphere Reserve (dashed line) and the community of Nuevo Becal (solid line).

in the dark phases and between 2:00 to 4:00 hr in the light phases (Figure 3d).

Although a higher percentage of records of Tapirella bairdii were recorded during dark moon phases in both sites with $58.89 \%(n=53)$ in CBR and $61.88 \%$ in NB ( $n$ = 86; Figure 4). The differences between dark and light moon phases within sites were not significant (CBR $t=$ 0.84478, g. $I .=9, P=0.210$; NB $t=1.5974, g . l .=9, P=$ 0.0723). Similarly, when comparing the light and dark moon phases for all ponds, a tendency was found for the dark phases, but it was not significant $(t=1.809 \mathrm{~g} . \mathrm{l}$. $=19, P=0.086$ ). When comparing between season we did not find any evidence of preference for any moon phase in both sites (CBR: $F^{3}{ }_{86}=0.773 ; P=0.3851 ; \mathrm{NB}: F^{3}{ }_{135}$ $=0.0505 ; P=0.480$; Figure 5 ).
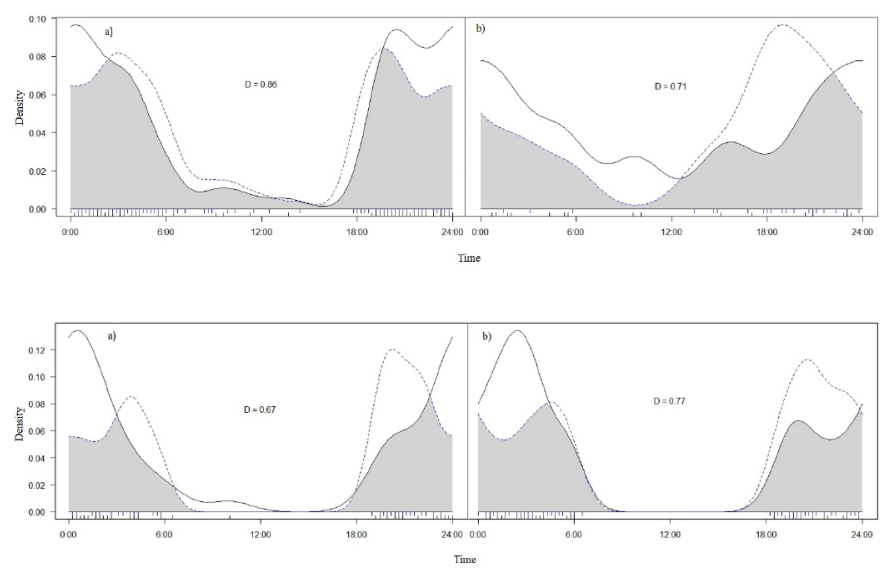

Figure 3. Proportion of overlap ( $D=$ level of overlap) in activity patterns of Tapirella bairdii in the Calakmul Biosphere Reserve (dashed line) and the community of Nuevo Becal (solid line) in dry season (a) and rainy season (b); and in activity patterns in the darks nights (dashed line) and ligth nigths (solid line) in the Calakmul Biosphere Reserve (c) and Nuevo Becal (d).

\section{Discussion}

Capture rate. Tapirs were more active in NB than in CBR or they are more abundant as have already been reported by Reyna-Hurtado and Tanner (2007) using track counts. Forest in NB is more humid with more water sources, a determining factor for tapirs. Moreover, the proportion of medium semi-perennial forest and low-flooded forest that 


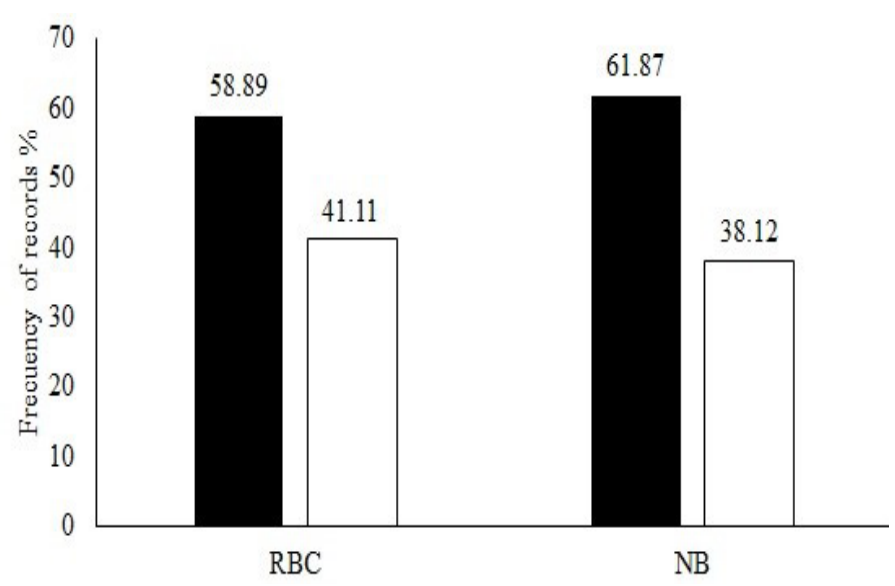

Figure 4. Records of Tapirella bairdii in the Calakmul Biosphere Reserve (CBR) and the community of Nuevo Becal (NB) in relation to moon phases: dark phases (in black) and light phases (in white).

tapirs tend to prefer, is higher in NB, in contrast with $C B R$ that is more covered by medium and low-dry forest (ReynaHurtado and Tanner 2007). Even though hunting pressure exist in NB, tapirs do not constitute a favorite prey species and therefore do not suffer from this threat. In fact, this relatively high activity of tapirs in NB highlights the importance of communal forests outside of protected areas to preserve large endangered species.

Activity Patterns. Tapirella bairdii was more active during the night with crepuscular activity peaks at dawn and twilight hours, a pattern that has been commonly observed in other neotropical areas (van Schaik and Griffiths 1996; Foerster and Vaughan 2002). Despite more frequent captures of tapirs during the dark moon phases in both sites, the results in general for all sites were not significant. This result is similar to the study of Tapirus terrestris in the Pantanal, Brazil (Coelho et al. 2008). However, when comparing the data between seasons, a preference for light moon phase was found for the dry season of CBR and for dark moon phases in both seasons in NB. In NB there was a general tendency to prefer the dark nights, tendency that was observed also with the activity peaks. In both sites tapir activity peaks in sunrise and in the sunset. However, in the nights with moon

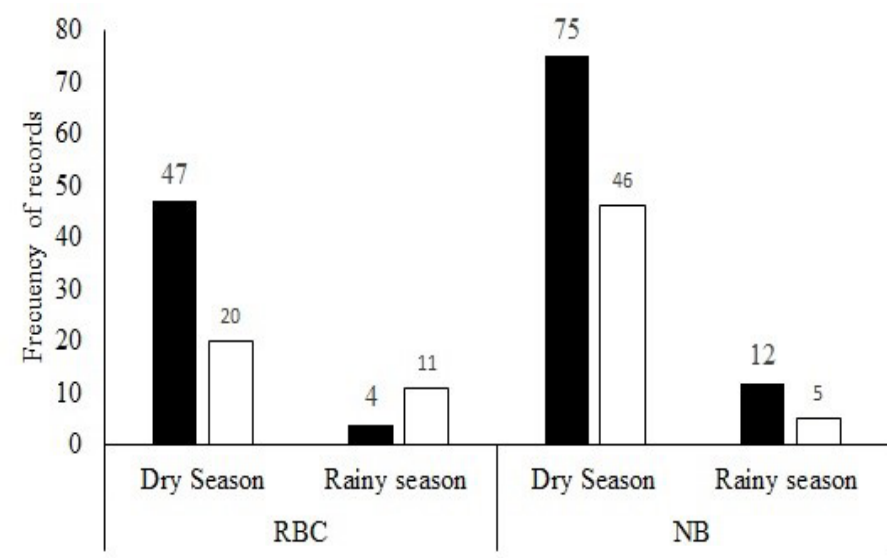

Figure 5. Records of Tapirella bairdii in the Calakmul Biosphere Reserve (CBR) and the community of Nuevo Becal (NB) in relation to moon phases: dark phases (in black) and light phases (in white), in the different seasons. light the activity peak for tapirs in CBR is between 0:00 and 1:00 hr while in NB is between 2:00 to 4:00 hr which coincide with the hours that the moon has settled down. These results suggest that tapirs prefer to move in dark nights and hours in NB than in CBR and that the human perturbation might have an effect on Tapirella bairdii behavior, as it is more active during dark moon phases in sites occupied by humans, probably in an effort to reduce predation risk or to minimize encounters with humans. As such, the intensity of the moon luminosity may modify the activity pattern of tapirs when they live in human perturbed forest.

It is also possible that the forest cover around the water sources, i. e. ponds, facilitate the visits of tapirs as it may act as camouflage. For example, Tapirus pinchaque were more active during full moon nights in closed habitats in Colombia (Lizcano and Cavalier 2000) while Tapirus terrestris reduced its movements in open habitats during the full moon nights in the Atlantic forest, Brazil (Medici 2010). Therefore, forest cover is a factor that should be taken in consideration in future studies of the moon light effects in tapirs.

In order to improve the study of the relationship between moon light tapir activity, we recommend setting up cameras randomly in the forest and not only at pond; this will allow to monitor a larger area and to obtain more records of their long displacement that will complement the current work. We also recommend estimating the relative abundance of predators, especially the jaguar (Panthera onca) which is the main predator of the tapirs in the Neotropical forest, because its activity could influence the tapir patterns.

To conclude, we hope that this study serves as a baseline to compare the behavior of tapirs in other regions and to evaluate the impact of human activities in the behavior of an endangered species. In some cases, altering the behavior of a species may have consequences at the population and ecosystem level, as was shown by elks (Cervus elaphus) altered behavior in Yellowstone National Park in USA (Laundré et al. 2010). We do not know the consequences at the population level of Tapirella bairdii when preferring dark nights, but it is a topic that deserves future attention. Finally, this information may be helpful to evaluate, select or adapt other study methods, for example, when capture attempts are made for radio-telemetry purposes, or for well-designed eco-tourism activities. Thus, this study can contribute to gain a better understanding of Tapirella bairdii behavior in relationship with moon phases and human perturbation, information that can be useful for conservations purposes.

\section{Acknowledgments}

Thanks to M. Briceño who kindly provided us with camera trap photos to carry out this research. We especially thank N. Arias for the field support, the Director of the Calakmul Biosphere Reserve and authorities of the community of Nuevo Becal. RRH appreciate the support that Conacyt Ciencia Básica provide through the grant \#182386. 


\section{Literature cited}

Camargo-Sanabria, A. A., and E. Mendoza. 2016. Interactions between terrestrial mammals and the fruits of two neotropical rainforest tree species. Acta Ecológica 73:45-52.

Carbajal-Borges, J. P., O. Godínez-Gómez, and E. Mendoza. 2014. Density, abundance and activity patterns of the endangered Tapirus bairdii in one of its last strongholds in southern Mexico. Tropical Conservation Science 7:100-114.

Coelho, I. P., L. F. B. Oliveira, And M. E. Oliveira. 2008. Does moonlight affect the use of natural licks by lowland tapir (Tapirus terrestris Linnaeus, 1758) in the Northeastern Brazilian Pantanal. Tapir Conservation 17:24.

Emmons, L. H., AND F. Feer. 1997. Neotropical rainforest mammals. A field guide. The University of Chicago Press. Chicago, U.S.A.

Foerster, C. R., and C. Vaughan. 2002. Home range, habitat use, and activity of Bairds Tapir in Costa Rica. Biotropica 34:423-437.

García-GIL, G. 2003. Colonización humana reciente y formación del paisaje agrario en la Reserva de la Biosfera de Calakmul, Campeche México. Tesis de Doctorado, Facultad de Filosofía y Letras. Universidad Nacional Autónoma de México. Ciudad de México, México.

Gaynor, K. M., C. E. Hojnowski., N. H. Carter, and J. S. Brashares. 2018. The influence of human disturbance on wildlife nocturnality. Science 360:1232-1235.

Griffiths, M., AND C. P van Schalk. 1993. The impact of human traffic on the abundance and activity periods of Sumatran rain forest wildlife. Conservation Biology 7:623-626.

Holden, J., A. Yanuar, And D. J. Martyr. 2003. The Asian Tapir in Kerinci Seblat National Park, Sumatra: evidence collected through photo-trapping. Oryx 37:34-40.

Laundré, J. W., L. Hernández, and W. J. Ripple. 2010. The landscape of fear: ecological implications of being afraid. Open Ecology Journal 3:1-7.

Lizcano, D. J., AND J. Cavalier. 2000. Daily and seansonal activity of the mountain tapir in the Central Andes of Colombia. Journal of Zoology 252:429-435.

Lizcano, D. J., and J. Cavalier. 2004. Using GPS collar to study Mountains Tapirs (Tapirus pinchaque) in the Central Andes of Colombia. Newsletter IUCN/SSC Tapir Specialist Group (TSG) 13:18-23.

Medicl, E. P. 2010. Assessing the viability of Lowland Tapir population in a fragmented landscape. Thesis Doctoral. University of Kent. Canterbury, U.S.A.

Meredith, M., ANd M. Ridout. 2014. Overview of the overlap package. R. Proj 1-9.

Naranjo, E., And E. Cruz. 1998. Ecología del tapir en la Reserva de la Biosfera La Sepultura. Acta Zoológica Mexicana 73:111125.

Norvarino, W., S. N. Kamilah., A. Nugroho., M. N. Janra., M. Silmi, AND M. Syafri. 2005. Habitat use and density of the Malayan Tapir (Tapirus indicus) in the Tartak Forest Reserve, Sumatra, Indonesia. Newsletter IUCN/SCC Tapir Specialist Group (TSG) 14:28-30.

Noss, J., R.L. Cuellar., J. Barrientos., L. Maffei., E. Cuellar., D. Arispe Rumiz, And K. Rivero. 2003. A camera trapping and radio telemetry study of Lowland Tapir (Tapirus terrestris) in Bolivia dry forests. Newsletter IUCN/SSC Tapir Specialist Group (TSG) 12:24-32.
O'Farrill, G., M. Galetti, and A. Campos-Arceiz. 2013. Frugivory and seed dispersal by tapirs: an insight on their ecological role. Integrative Zoology 8:4-17.

Padilla, M., AND R. C. Dowler. 1994. Tapirus terrestris. Mammalian Species 481:1-8.

Pennington, T. D., And J. Sarukhán. 1998. Árboles tropicales de México. UNAM-Fondo de Cultura Económica. Ciudad de México, México.

Prugh, L. R., And C. D. Golden. 2014. Does moonlight increase predation risk? Meta-analysis reveals divergent responses of nocturnal mammals to lunar cycles. Journal of Animal Ecology 83:504-514.

R CORE TEAM. 2018. R: A language and environment for statistical computing. R Foundation 503 for Statistical Computing, Vienna, Austria.

Randall, D., W. Burggren, And K. French. 1998. Fisiología animal. mecanismos y adaptaciones. McGraw-Hill Interamericana. Madrid. España.

Reyna-Hurtado, R., And G. W. Tanner. 2007. Ungulate relative abundance in hunted and not-hunted sites in Calakmul Forest (Southern Mexico). Biodiversity and Conservation 16:743-756.

Reyna-Hurtado, R. 2009. Conservation status of the whitelipped peccary (Tayassu pecari) outside the Calakmul Biosphere Reserve in Campeche, Mexico: a synthesis. Tropical Conservation Science 2:159-172.

Reyna- Hurtado, R., G. O' Farril., D. Sima., M. Andrade., A. Padilla, AND L. Sosa. 2010. Las aguadas de Calakmul: Reservorios de la vida Silvestre y de la riqueza natural de México. Biodiversitas 93:1-6.

Ripple, W. J., E. J. Larsen., R. A. Renkin, and D. W. Smith. 2001. Trophic cascades among wolves, elk and aspen on Yellowstone National Parks northern range. Biological Conservation 102:227-234.

Ridout, M.S., AND M. Linkie. 2009. Estimating overlap of daily activity patterns from camera trap data. Journal of Agricultural, Biological and Environmental Statistics 14:32-337.

Ruiz-García, M., Castellanos, A., de Thoisy, B., Vásquez, C., Kaston, K., Shostell, J., Pinedo-Castro, and S. Sandoval. 2012. Phylogeography of the Mountain Tapir (Tapirus pinchaque) and the Central American Tapir (Tapirus bairdii) and the origins of the three Latin-American tapirs by means of mtCyt-B sequences. Pp. 83-116 in Current Topics in Phylogenetics and Phylogeography of Terrestrial and Aquatic Systems. (Anamthawat-Jónsson, K., ed.). InTech. Rijeka, Croatia.

SEMARNAT. 2010. Norma Oficial Mexicana NOM-059Ecol-2010. Protección ambiental, especies nativas de México de flora y fauna silvestres, categorías de riesgo y especificaciones para su inclusión, exclusión o cambio. Lista de especies en riesgo. Diario Oficial de la Federación, 30 diciembre 2010.

Tobler, M. W. 2002. Habitat use and diet of Baird's Tapirs (Tapirus bairdii) in a montane cloud forest of the Cordillera de Talamanca, Costa Rica. Biotropica 34:468-474.

UICN (Unión Internacional para la Conservación de la Naturaleza). Disponible en: www.iucnredlists.org. Consulted on August $21^{\text {th }} 2015$.

van Schaik, C. P., and M. Griffiths. 1996. Activity periods of Indonesia rain forest mammals. Biotropica 28:105-112. 
Wallace, R., G. Ayala, and H. Gómez. 2002. Lowland tapir activity patterns and capture frequencies in lowland moist tropical forest. Newsletter IUCN/SSC Tapir Specialist Group (TSG) 11:1.

ZAR, J. H. 2010. Biostatistical analysis. Pearson Education. New Jersey, U.S.A.

Associated editor: Jorge Servín

Submitted: July 20, 2018; Reviewed: September 7, 2018;

Accepted: November 2, 2019; Published on line: November 26, 2019. 